\title{
Vitamin D replacement in Asians with diabetes may increase insulin resistance
}

\author{
A V G Taylor, P H Wise
}

\begin{abstract}
Summary
We report three cases of vitamin $D$ replacement in British Asians with vitamin D deficiency and non-insulin-dependent diabetes mellitus. In all cases, replacement resulted in an increase in insulin resistance and a deterioration of glycaemic control.
\end{abstract}

Keywords: vitamin D replacement; Asians; diabetes; insulin resistance

Vitamin D deficiency is one of the many environmental factors which may be implicated in the pathogenesis of non-insulin-dependent diabetes. ${ }^{1}$ In particular, it may play an important role in Asians, in whom there is a high prevalence of both diabetes and osteomalacia. Vitamin D receptors are present on pancreatic islet cells and deficiency of both calcium and vitamin D leads to impaired insulin levels in experimental animals ${ }^{2}$ and humans. ${ }^{34}$ An improvement in insulin secretion has been demonstrated following treatment with vitamin $\mathrm{D}$ in Asians considered to be at risk of diabetes ${ }^{5}$ but the effects of vitamin D repletion in established diabetes are not clear. We report three cases of the effects of repletion with vitamin D on glycaemic control in vitamin D deficient Asians with non-insulin-dependent diabetes.

\section{Case reports}

Two South Asian men and one woman with non-insulin-dependent diabetes were identified from a larger screening programme of vita-

Table 1 Changes in 25-hydroxy vitamin D3, glycosylated haemoglobin and triglycerides before and after treatment with vitamin $\mathrm{D}$

\begin{tabular}{|c|c|c|c|c|c|c|}
\hline \multirow[b]{2}{*}{ Patient } & \multicolumn{2}{|c|}{$25 \mathrm{OHD} 3$ (nmolll) } & \multicolumn{2}{|c|}{$H b A_{l} C(\%)$} & \multicolumn{2}{|c|}{ Triglycerides (mmolll) } \\
\hline & Before & 3/12 After $R x$ & Before & 3/12 After $R x$ & Before & 3/12 After $R x$ \\
\hline 1 & 13 & 51 & 8.8 & 9.9 & 1.28 & 1.66 \\
\hline 2 & 13 & 47 & 7.5 & 8.9 & 1.54 & 2.88 \\
\hline 3 & 8 & 33 & 8.5 & 9.0 & 1.51 & 2.01 \\
\hline
\end{tabular}

Table 2 Changes in fasting glucose insulin and insulin resistance before and after treatment with vitamin D

\begin{tabular}{|c|c|c|c|c|c|c|}
\hline \multirow[b]{2}{*}{$N$} & \multicolumn{2}{|c|}{ Fasting glucose (mmolll) } & \multicolumn{2}{|c|}{ Fasting insulin (mIU/l) } & \multicolumn{2}{|c|}{ Insulin resistance (FIRI index) } \\
\hline & Before $R x$ & 3/12 after $R x$ & Before $R x$ & $3 / 12$ after $R x$ & Before $R x$ & $3 / 12$ after $R x$ \\
\hline 1 & 8.2 & 12.8 & 8.5 & 14.3 & 2.79 & 7.32 \\
\hline 2 & 11.4 & 15.5 & 3.0 & 15.8 & 1.37 & 9.8 \\
\hline 3 & 8.0 & 10.4 & 3.7 & 3.7 & 1.18 & 1.54 \\
\hline
\end{tabular}

min $\mathrm{D}$ deficiency in the local Asian community. All were found to be vitamin $\mathrm{D}$ deficient as defined by $25-\mathrm{OH}$ vitamin $\mathrm{D}$ (25-OH-D3) levels of less than $15 \mathrm{nmol} / \mathrm{l}$ from venous blood samples taken at the end of spring. Repeat samples taken 3 months later during a very hot summer confirmed vitamin $\mathrm{D}$ deficiency but parathyroid hormone, calcium, albumin, alkaline phosphatase and renal function were all in the normal range. Each subject was offered and received vitamin $\mathrm{D}$ replacement in the form of $300000 \mathrm{IU}$ ergocalciferol by intramuscular injection.

Venous blood samples for glycosylated haemoglobin $(\mathrm{Hb})$, cholesterol, triglycerides, fasting insulin and glucose were collected prior to and three months after treatment. 25-OH-D3 levels were also repeated three months after treatment. Results are shown in tables 1 and 2. Insulin resistance was assessed by the FIRI index (fasting serum insulin $(\mathrm{mU} / \mathrm{l}) \times$ fasting serum glucose $(\mathrm{mmol} / \mathrm{l}) / 25){ }^{6}$

For each patient, a marked rise in 25-OH-D3 levels was observed 3 months following vitamin $\mathrm{D}$ administration resulting in levels within the normal range. This was associated with both an increase in fasting insulin levels in two of three subjects and insulin resistance in all three subjects. There was an increase in glycosylated $\mathrm{Hb}$ during the observation period and a rise in serum triglycerides.

\section{Discussion}

Vitamin D deficiency still affects up to $20 \%$ of adult Asians in the British Asian community, ${ }^{7}$ despite efficient methods of prevention such as the annual administration of high dose intramuscular calciferol used in these three cases. The pathogenesis is multifactorial and involves reduced UV radiation exposure and dietary factors. ${ }^{8}$ Both these factors apply particularly to female Asians who are more likely to wear traditional dress and practice strict vegetarianism, and it is perhaps surprising that only one of our subjects was female.

There is little doubt that vitamin $\mathrm{D}$ replacement increases pancreatic B cell function, ${ }^{3-5}$ but its benefits are less certain. Glucose tolerance has been observed both to improve ${ }^{9}$ and remain unchanged ${ }^{5}$ in patients with impaired glucose tolerance. In established diabetes no major effect has been reported, ${ }^{10}$ except where large doses of vitamin $\mathrm{D}$ have been used in the treatment of osteomalacia. ${ }^{11}$ The magnitude of increase in insulin secretion 
may relate both to duration of diabetes ${ }^{10}$ and to the severity of vitamin $\mathrm{D}$ deficiency and it has been suggested that vitamin $\mathrm{D}$ may play an important role in diabetes prevention in at-risk groups. $^{5}$

Our observations suggest that vitamin D replacement may have a detrimental effect on glycaemic control in established diabetes. Although there was an increase in fasting insulin levels in two of the cases, as has been noted by others, ${ }^{35}$ our results suggest that the lack of perceived benefit on glycaemic control may be explained by an increase in insulin resistance. We are not aware of any previous similar reports but our findings rely on the FIRI index, which has not been fully validated against the

1 Boucher BJ. Strategies for reduction in the prevalence of NIDDM; the case for a population-based approach to the development of policies to deal with environmental factors in its aetiology. Diabetologia 1995;38:1125-9.

2 Beaulieu C, Kestekian R, Havrankova J, Gascon-Barre M Calcium is essential in normalizing intolerance to glucose that accompanies vitamin D depletion in vivo. Diabetes that accompani42:35-43.

3 Gedik O, Akalin S. Effects of vitamin D deficiency and repletion on insulin and glucagon secretion in man. Diabeto logia 1986;29:142-5.

4 Kumar S, Davies M, Zakaria Y, et al. Improvement in glucose tolerance and beta-cell function in a patient with vitamin $\mathrm{D}$ deficiency during treatment with vitamin $\mathrm{D}$. Post grad Med $\mathcal{F}$ 1994;70:440-3.

5 Boucher BJ, Mannan N, Noonan K, Hales CN, Evans SJW. Glucose intolerance and impairment of insulin secretion in relation to vitamin $\mathrm{D}$ deficiency in East London Asian Diabetologia 1995;38:1239-45.

6 Duncan MH, Singh BM, Wise PH, Carter G. A simple measure of insulin resistance (letter). Lancet 1995;436:120-1. gold standard of measuring insulin resistance by the glucose clamp technique. Furthermore, it was not possible to exclude the influence of changes in lifestyle such as an alteration in diet or exercise level. Nevertheless, the Asian community is known to represent a group at particular risk of insulin resistance, which has recently been suggested to be an independent risk factor for ischaemic heart disease. ${ }^{12}$ If our observations are reproducible, they question the benefit of vitamin $\mathrm{D}$ replacement in those with evidence of deficiency, especially in view of the associated effects on lipids. Vitamin D prophylaxis in the Asian community may circumvent such a problem.

7 Finch PJ, Ang L, Eastwood JB, Maxwell JD. Clinical \& histological spectrum of osteomalacia among Asians in S London. $Q 7$ Med, New Ser 1992;83:439-48.

8 Henderson JB, Dunnigan MG, McIntosh WB, Motaal AA Hole $\mathrm{D}$. Asian osteomalacia is determined by dietary factors when exposure to ultraviolet radiation is restricted: a risk factor model. $Q \mathcal{F} \mathrm{Med}$ 1990;76:923-33.

9 Bansal S, Rizvi SNA, Rao MB, et al. Effect of hypocalcaemia on glucose tolerance, insulin release and free fatty acid levels in human subjects. Postgrad Med 1975;52:471-5.

10 Orwoll E, Riddle M, Prince M. Effects of vitamin D on insulin and glucagon secretion in non-insulin-dependen diabetes mellitus. Am f Clin Nutr 1994;59:1083-7.

11 Kocian J. Diabetic osteopathy: favourable effect of treatmen with osteomalacia with vitamin $\mathrm{D}$ and calcium on high blood glucose levels. Vnitr Lek 1992;4:352-6.

12 Despres J-P, Lamarche B, Mauriege P, et al. Hyperinsuline$\mathrm{mia}$ as an independent risk factor for ischemic heart disease. $N$ Engl f Med 1996;334:952-6.

Carlo Forlanini (1847-1918) was born in Milan, son of a doctor. He qualified as MD in Pavia (1870), worked at Ospedale Maggiore (1871-84) on skin and eye tuberculosis, and became Professor of Medicine in Turin in 1884. In 1889 he moved to Pavia where he became Professor of Medical Pathology (1889), Professor of Medicine, (1900) and Senator (1913). He died in Nervia in 1918. He is commemorated by the Carlo Forlanini Institute for Tuberculosis in Rome, which was founded in 1934. - D G Fames 